\title{
Long-term changes in water flow of the Volga basin rivers
}

\author{
Irina Milyukova ${ }^{1}$, Aleksandr Georgiadi ${ }^{1 *}$, and Oleg Borodin ${ }^{2}$ \\ ${ }^{1}$ Institute of Geography, RAS, Moscow, Russia \\ ${ }^{2}$ Institute of Water Problems, Russian Academy of Sciences, Russia
}

\begin{abstract}
The long periods/phases (with a duration of more than 10-15 years) of increased and decreased water flow of rivers in the Volga river basin were identified. The annual and seasonal water flow (over snow-melt flood period, as well as summer-autumn and winter low-water seasons) of six representative rivers over observation periods more than a century in duration, starting from the 1870 s-1890s up to 2016 , was used. In addition to this, periods with the average runoff close to its normal value were also observed. The boundaries of contrast phases were determined using normalized cumulative deviation curves in combination with Student's test of the statistical homogeneity of the data series. The duration of the phases varies from 10 to 96 years. The phases of lower runoff were generally longer than those of higher runoff (this is especially typical of the winter and summer-autumn low-water season). The identified contrast phases show a statistically significant difference between the annual and seasonal runoff. The analysis of the data series of alteration of phases with increased and decreased water flow in hydrological seasons of the year allowed the authors to identify three major types of their long-term dynamics within the Volga river basin.
\end{abstract}

\section{Introduction}

Long-term variations of the annual and seasonal river runoff show periods (phases) of its decreased and increased values with different duration. Long contrast phases with a duration of 10-15 and more years can be identified in them. They are observed against the background of appropriate climate changes. Anthropogenic factors cause considerable changes in these phases [1-5].

The article presents the results of comparison of contrast phase characteristics of six representative rivers in the Volga basin over more than century-long observation periods (starting from the 1870-1890s), which feature considerable differences in natural conditions and the character of anthropogenic load.

The objects of the study were chosen to be four rivers in the taiga zone (the Unzha at Makar'ev, watershed area of $18500 \mathrm{~km}^{2}$; the Vyatka at Kirov, $48300 \mathrm{~km}^{2}$; the Kama at Perm (Kama HPP), $169000 \mathrm{~km}^{2}$ ); in the zone of mixed and broad-leaved forests (the Volga

\footnotetext{
*Corresponding author: georgiadi@igras.ru
} 
at Staritsa, $21100 \mathrm{~km}^{2}$, the Oka at Kaluga, $54900 \mathrm{~km}^{2}$; and the forest-steppe zone (the Belaya at Birsk, $121000 \mathrm{~km}^{2}$ ).

\section{The methods used to analyze the annual and seasonal runoff}

The approach to the analysis of the long-term phases of changes in the annual and seasonal runoff caused by climate changes is based on the analysis of data series of conditionally natural runoff (with exclusion of changes caused by anthropogenic impact) with the use of cumulative deviation curves, statistical homogeneity criteria of average runoff values, and the comparison of the characteristics of the identified phases of contrast water flow.

The cumulative deviation curves represent a cumulative sum of deviations of a characteristic from its normal annual value, calculated for the entire observation period. In many cases, the deviations are normalized by the coefficient of variation to enable the comparison of temporal changes in different types of characteristics. The cumulative deviation curves reveal long-term periods (phases), within which the characteristic takes on values below or above its normal annual value (relative to the normal annual runoff, calculated for the entire observation series).

The boundaries of hydrological seasons (spring flood and low-water seasons) were determined using runoff hydrographs throughout the observation period. The data on the long-term dates of the beginning and the end of snow flood and winter freeze-up were also used.

In many rivers of Russia, the long-term series of their mean annual and seasonal runoff are not homogeneous from the viewpoint of the impact of anthropogenic factors on it and consist of two parts. Among the rivers under consideration, only the runoff of the Kama at Perm/Kama HPP has changed considerably under the regulating effect of the Kama Reservoir. The first part (1881-1953) of the entire observation series of the Kama contains long-term data referring to the period before the beginning of an appreciable impact of anthropogenic factors. The second part consists of a long series, in which the annual runoff has changed to a different degree under the effect of anthropogenic factors (mostly, due to the reservoir). Therefore, the flow for this period was naturalized. This was made with the use a method for transformation of the annual hydrograph of daily water discharges with the use of the influence function proposed by G.P. Kalinin and P.I. Milyukov [6]. The naturalized part of the long-term runoff series was combined with its other part, in which the runoff was not appreciably disturbed by anthropogenic impact. The obtained data were used to form joint series of conditionally natural mean annual and seasonal runoff.

The boundary (shift points) between the long phases of increased/decreased runoff values was taken to coincide with the minimal and maximal coordinate values of the cumulative deviation curves in combination with Student's test. The long phases of increased water flow correspond to a steady long-term trend toward an increase in the ordinates of the cumulative deviation curve, and the phases of decreased water flow correspond to a decrease in its ordinates. Shorter periods of flow variation can be seen against the background of such long tendencies.

\section{Long phases of multi-year changes of the conditionally natural mean annual and seasonal runoff}

\subsection{The main types of temporal dynamics of long phases}

Fig. shows the three major types of the consequences of changes in the long phases of increased and decreased mean annual and seasonal water flow in representative rivers of the 
Volga Basin. The first type includes the Volga at Staritsa, the Oka at Kaluga, and the Belaya at Birsk. In these rivers, since the start of the observation period, the winter and summer-autumn low-water seasons showed a phase of decreased values, which changed to the phase of its increased values in the 1960s-1980s. An inverse picture was observed for the snow-melt flood flow. The observation period in this case began from a phase of increased runoff. After it, at the late 1960s-early 1970s (in the early 1960s, in the case of the Belaya River), a phase of decreased snow-melt flood flow began. In the summer and autumn runoff in the Belaya and the Oka, the phase of the decreased runoff in the late XIXearly XX centuries is preceded by another phase of its increased runoff. In addition, in the 2000 s, a passage from the phase of increased to that of decreased runoff in the summerautumn period possibly was taking place. The pattern of long-term changes in the mean annual runoff in these rivers is far more complex. Four contrast phases can be identified.

Oka-Kaluga
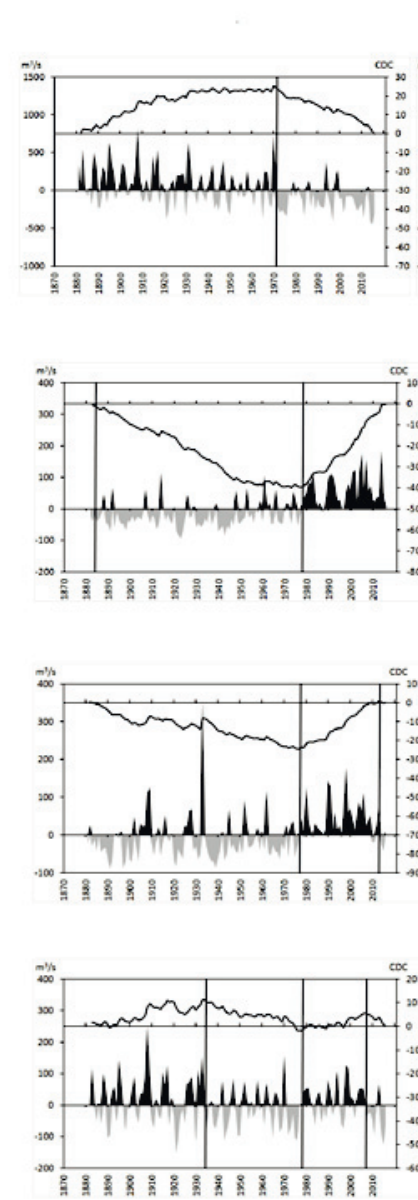

Kama-Perm' snow-melt flood flow

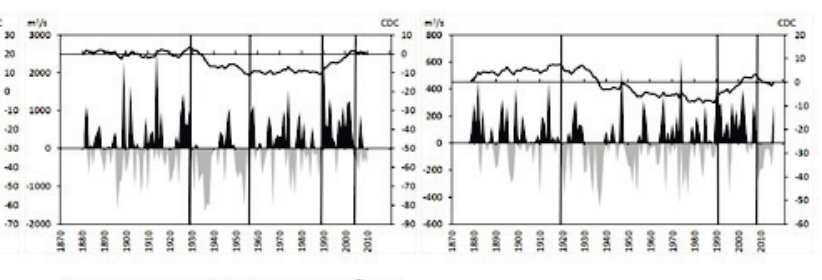

summer-autumn water flow

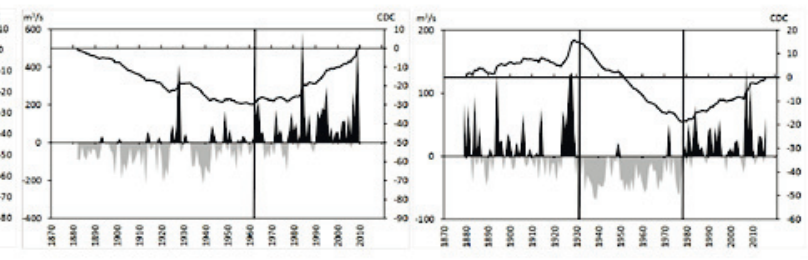

winter water flow
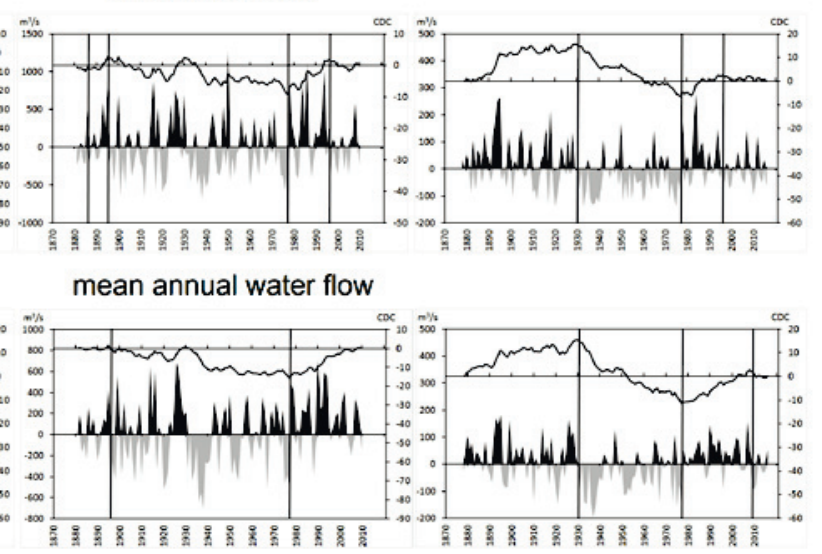

Fig. The main types of the long-term changes in naturalized mean annual and seasonal water flow. Type 1 (on the example of Oka at Kaluga), type 2 (on the example of Kama at Perm') and type 3 (on the example of Vyatka at Kirov). Positive (black) and negative (grey) deviations from long-term average runoff; curves - normalized cumulative deviation curves (CDCs). The vertical black lines show phase boundaries (shift points) of increased/decreased values of the naturalized water flow. 
For the second type of the dynamics of contrast phases (this group includes the Kama at Perm and the Unzha at Makar'ev), the mean annual and seasonal runoff show two major long-term phases of flow variations, the changes of which were quasi-synchronous (Fig.). It should be mentioned, however, that the snow-melt flood flow in the Kama, since the start of the observation period, shows a phase, during which the runoff was close to the normal value calculated for the entire observation period. A similar phase can be also seen in the 1950s-1980s. Note also that in the 1990s-2000s, the runoff of the snow-melt flood and the summer-autumn low-water season showed a change from the phase of increased to that of decreased water flow.

In the Vyatka at Kirov, for which the third type of the change of contrast phases was identified, this change was taking place synchronously for both the runoff of the hydrological seasons of the year and the mean annual one (Fig.). In this river, a change in the runoff of snow-melt flood, of summer-autumn period and in the mean annual was taking place in the 1990s-2000s, which could be interpreted as a start of a phase of their decreased values.

Note that the change of the phases of increased/decreased runoff often takes place within relatively short time intervals.

\subsection{The duration of the long phases}

The time boundary in the change of the long phases of increased and decreased flow varies appreciably for the mean annual runoff and that of hydrological seasons either for a single river or between the rivers. The duration of the phases also varies within wide limits (from 10 to 96 years). Commonly, the duration of the longest phases of decreased water flow is longer (often considerably) than the duration of phases of increased water flow (with the exception of the spring flood flow in the Oka at Kaluga and in the Volga at Staritsa, as well as the runoff of the winter and summer-autumn low-water seasons in the Vyatka at Kirov).

\subsection{Differences between the average runoff of contrast phases}

The long-term phases of increased/decreased water flow feature considerable differences between their average runoff values. Thus, for the snow-melt flood flow, this difference varies from $15 \%$ in the Vyatka to $36 \%$ in the Oka (relative to the runoff in the phase of its decreased values), and that for the summer-autumn flow is $22 \%$ in the Kama and $48 \%$ in the Unzha; for the runoff of the winter low water season, this difference is $30 \%$ in the Kama and $143 \%$ in the Oka; the difference for the mean annual runoff is $14 \%$ in the Kama and $27 \%$ in the Unzha.

\section{Conclusions}

The analysis of long-term series of the mean annual and seasonal (over spring flood period, as well as summer-autumn and winter low-water seasons) runoff of six representative rivers in the Volga basin (the Volga at Staritsa, the Oka at Kaluga, the Unzha at Makar'ev, the Vyatka at Kirov, the Kama at Perm, and the Belaya at Birsk) over observation periods more than a century in duration, starting from the $1870 \mathrm{~s}-1890$ s up to 2016 was used to identify long-term phases (with a duration of more than 10-15 years) of their increased and decreased values. In addition to this, periods with the average runoff close to its normal value were also observed in some cases. The boundaries of contrast phases were determined using normalized cumulative deviation curves and Student's test. The duration of the phases varies from 10 to 96 years. The phases of decreased flow were generally 
longer than those of increased one (this is especially typical of the winter and summerautumn low-water season). The identified phases show a statistically significant difference between the annual and seasonal runoff. It is $14-27 \%$ for the mean annual runoff, $15-36 \%$ for snow-melt flood flow, 22-48\% for summer-autumn low-water period runoff, and 30 $143 \%$ for winter low-water season runoff.

Note that, since the mid-1990s to the early 2000s, the major part of the Volga basin showed a possible tendency toward a change to a phase of increased flow, which has already been observed before the 1970-1980s.

The analysis of the series of alteration of phases with increased and decreased water flow in hydrological seasons of the year allowed three major types of the series of changes in the contrast phases of water flow to be identified.

The obtained results support the conclusion made earlier [1-5] for large and mediumsize rivers in Russia: the long-term phases of increased/decreased water flow (with duration of 10-15 years and more) are a typical feature of long-term changes of the mean annual and seasonal runoff. The differences between their average values are generally statistically significant. Long-term contrast phases occurred repeatedly in some rivers within long observation periods, including phases of increased flow, in particular, the one that was recorded in many Russian rivers since the 1970s-1980s and coincided in time with global climate warming.

The work was done within a State assignment of the Institute of Geography RAS No. 0148-20190007, State registration No. AAAA-A19-119021990093-8, and with financial support received from the RFBR (project no. 18-05-00479).

\section{References}

1 M.V. Bolgov, I.A. Filippova, N.V. Osipova, E.A. Korobkina, and M.D. Trubetskova, Problems of Geography, 145, 206 (2018) (in Russian)

2 A.G. Georgiadi, N.I. Koronkevich, I.P. Milyukova, E.A. Kashutina, and, E.A. Barabanova, Present-day and scenario changes in river runoff in largest russian rivers, part 2, Basins of the Volga and Don rivers (Maks Press, Moscow, 2014) (in Russian)

3 A.G. Georgiadi, E.A. Kashutina, I.P. Milyukova, Polarforschung, 87 (2), 167 (2018) DOI: 10.2312 /polarforschung.87.2.167

4 A.G. Georgiadi, N.I. Koronkevich, I.P. Milyukova, E.A. Barabanova, Basic and App. Clim. 2, 55 (2016) (in Russian). DOI 10.21513/2410-8758-2016-2-55-78

5 Water Resources of Russia and Their Use (State Hydrological Institute, St. Petersburg, 2008) (in Russian)

6 G.P. Kalinin, P.I. Milyukov, Proceed. Central Forecast Inst. 66, 1 (1958) (in Russian) 